\title{
Children with obesity have cardiac remodeling and dysfunction: a cine DENSE magnetic resonance imaging study
}

\author{
Cassi M Binkley ${ }^{1 *}$, Linyuan Jing ${ }^{2}$, Jonathan D Suever ${ }^{2}$, Nivedita Umasankar ${ }^{2}$, Gregory J Wehner ${ }^{3}$, Sean M Hamlet ${ }^{2}$, \\ David Powell ${ }^{4}$, Aurelia Radulescu ${ }^{2}$, Frederick H Epstein ${ }^{5}$, Brandon K Fornwalt ${ }^{2}$
}

From 18th Annual SCMR Scientific Sessions

Nice, France. 4-7 February 2015

\section{Background}

Obesity affects one in five children in the US and these children tend to maintain excess weight into adulthood. It has recently been shown that childhood obesity is associated with both cardiac remodeling (hypertrophy) and contractile dysfunction. However, the etiology of these cardiac changes is not well understood. We hypothesized that cardiac remodeling and dysfunction could not be entirely explained by elevations in blood pressure and that excess abdominal and epicardial adiposity may also correlate with cardiac changes.

\section{Methods}

Healthy weight $\left(5^{\text {th }}-85^{\text {th }}\right.$ percentile for age and height) and obese $\left(\geq 95^{\text {th }}\right.$ percentile) children between the ages of 8 and 18 were recruited. All subjects underwent MRI on a 3T Siemens Tim Trio scanner using a 6 element chest coil and 24 element spine coil. Cine SSFP images were used to quantify cardiac remodeling (left ventricular mass and thickness) and epicardial adiposity. Displacement Encoding with Stimulated Echoes (DENSE) was used to quantify cardiac strains and torsion with base, mid, and apical short axis images and 2- and 4-chamber long axis views. Phase contrast imaging was used to measure diastolic filing velocities and T1 weighted imaging was used to quantify subcutaneous and visceral adiposity using a transverse slice at the L4-L5 disc. Blood pressure was averaged from two readings at a resting state by auscultation, using an aneroid sphygmomanometer, and an appropriate sized cuff.

Physiology, University of Kentucky, Lexington, KY, USA

Full list of author information is available at the end of the article

\section{Results}

Sixteen obese children (ages 12.2 $\pm 2.9,63 \%$ female) and 15 healthy controls (ages $13.5 \pm 2.3,60 \%$ female) were enrolled. Children with obesity had a left ventricular mass index (LVMI) that was increased by $28 \%$ compared to healthy controls $(\mathrm{p}<0.001)$. Children with obesity also showed a $40 \%$ reduction in E/A ratio compared to the control group $(p=0.01)$. There were no differences in ejection fraction, end systolic or end diastolic volumes between the two groups. However, we observed a $14 \%$ reduction in global, peak longitudinal strain in children with obesity $(p=0.03$, Figure 1$)$, suggesting impairment of contractile function in the left ventricle. Additionally, children with obesity had more than double the amount of visceral adiposity, subcutaneous adiposity, and epicardial adipose tissue. Systolic blood pressure was weakly positively correlated with LVMI $(\mathrm{r}=0.4, \mathrm{p}=0.025)$ and longitudinal strain $(\mathrm{r}=0.54, \mathrm{p}=$ $0.002)$. Visceral and deep subcutaneous adiposity were also weakly positively correlated with LVMI $(r=0.37$, $\mathrm{p}=0.04$ and $\mathrm{r}=0.42, \mathrm{p}=0.02$, respectively). Epicardial adiposity was more strongly correlated with longitudinal strain $(\mathrm{r}=0.6, \mathrm{p}<0.001)$, suggesting that epicardial fat could contribute to reduced contractile function.

\section{Conclusions}

Cardiac remodeling and dysfunction are present in children with obesity as evidenced by increased left ventricular mass and reduced longitudinal strain. These changes in structure and function in the heart are correlated with measures of systolic blood pressure and the amount of epicardial fat. 


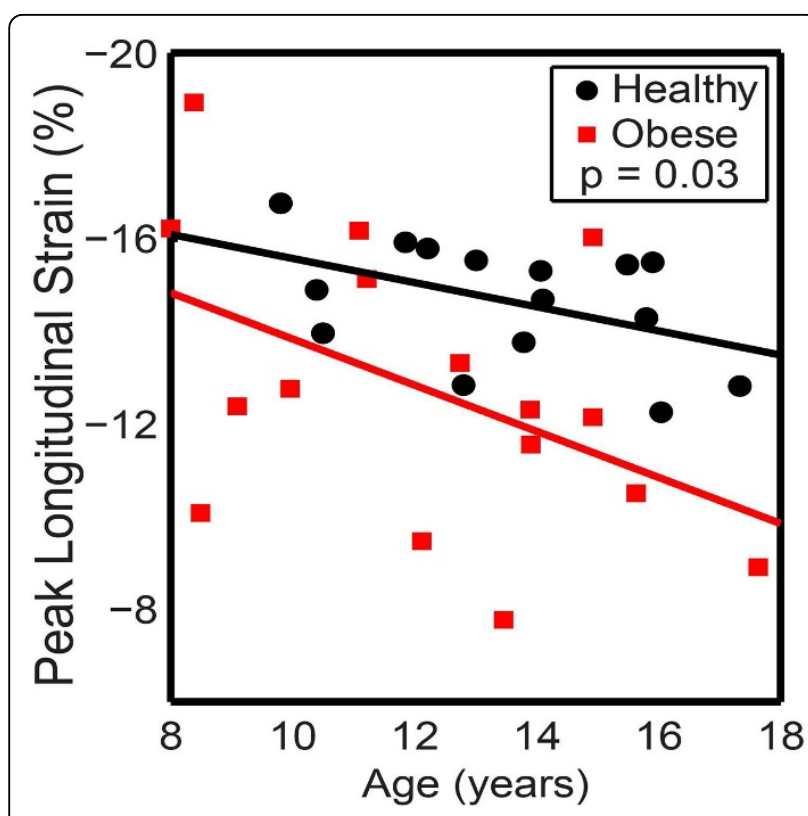

Figure 1 Children with obesity have reduced peak longitudinal strain compared to healthy controls.

\section{Funding}

This project was supported by a grant from the National Institute of General Medical Science (P20 GM103527) of the National Institutes of Health; the University of Kentucky Cardiovascular Research Center; the National Center for Research Resources and the National Center

Table 1 Children with obesity have cardiac remodeling and dysfunction

\begin{tabular}{lccc}
\hline & $\begin{array}{c}\text { Obese, } \\
\mathrm{n}=16\end{array}$ & $\begin{array}{c}\text { Healthy, } \\
\mathrm{n}=15\end{array}$ & $\mathrm{p}$ value \\
\hline Left Ventricular Mass Index (g/m^2.7) & $29 \pm 4$ & $22 \pm 3$ & ${ }^{*}<0.001$ \\
\hline $\begin{array}{l}\text { Average Left Ventricular } \\
\text { Thickness (mm) }\end{array}$ & $6 \pm 0.8$ & $5.3 \pm 0.8$ & ${ }^{*} 0.013$ \\
\hline E/A Ratio & $58 \pm 6$ & $54.8 \pm 6$ & 0.19 \\
\hline Ejection Fraction (\%) & $132 \pm 30$ & $144 \pm 35$ & 0.34 \\
\hline End Diastolic Volume (mL) & $56 \pm 14$ & $65 \pm 17$ & 0.14 \\
\hline End Systolic Volume (mL) & $33.5 \pm 9$ & $28.6 \pm 12$ & 0.22 \\
\hline Peak Radial Strain (\%) & $17.8 \pm 2$ & $18.3 \pm 2$ & 0.51 \\
\hline Peak Circumferential Strain (\%) & $12.7 \pm 3$ & $14.6 \pm 1$ & ${ }^{*} 0.03$ \\
\hline Peak Longitudinal Strain (\%) & $4 \pm 1$ & $3.6 \pm 2$ & 0.26 \\
\hline Torsion (\%/cm) & $115 \pm 10$ & $105 \pm 8$ & ${ }^{*} 0.007$ \\
\hline Systolic Blood Pressure (mmHg) & $75 \pm 7$ & $68 \pm 5$ & ${ }^{*} 0.005$ \\
\hline Diastolic Blood Pressure (mmHg) & $88 \pm 7$ & $80 \pm 5$ & ${ }^{*} 0.002$ \\
\hline Mean Arterial Pressure (mmHg) & $60 \pm 8$ & $30 \pm 13$ & ${ }^{*}<0.001$ \\
\hline Subcutaneous Fat (\% of body cavity) & $34 \pm 9$ & $15 \pm 8$ & ${ }^{*}<0.001$ \\
\hline Visceral Fat (\% of visceral cavity) & $1219 \pm 653$ & $532 \pm 316$ & ${ }^{*} 0.002$ \\
\hline Epicardial Fat mm^2 & & &
\end{tabular}

* denotes $p<0.05$ for Advancing Translational Sciences, National Institutes of Health (UL1TR000117), and contributions made by local businesses and individuals through a partnership between Kentucky Children's Hospital and Children's Miracle network. The content is solely the responsibility of the authors and does not necessarily represent the official views of the funding sources.

\section{Authors' details}

'Physiology, University of Kentucky, Lexington, KY, USA. ${ }^{2}$ Pediatrics, University of Kentucky, Lexington, KY, USA. ${ }^{3}$ Biomedical Engineering, University of Kentucky, Lexington, KY, USA. ${ }^{4}$ Radiology, University of Kentucky, Lexington, KY, USA. ${ }^{5}$ Biomedical Engineering, University of Virginia, Charlottesville, VA, USA.

Published: 3 February 2015

doi:10.1186/1532-429X-17-S1-Q57

Cite this article as: Binkley et al: Children with obesity have cardiac remodeling and dysfunction: a cine DENSE magnetic resonance imaging study. Journal of Cardiovascular Magnetic Resonance 2015 17(Suppl 1):Q57.
Submit your next manuscript to BioMed Central and take full advantage of:

- Convenient online submission

- Thorough peer review

- No space constraints or color figure charges

- Immediate publication on acceptance

- Inclusion in PubMed, CAS, Scopus and Google Scholar

- Research which is freely available for redistribution 